\title{
Influence of a novel classification of the papilla of Vater on the outcome of needle-knife fistulotomy for biliary cannulation
}

Jorge Canena ${ }^{1,3,4,7^{*}+}$, Luís Lopes ${ }^{2,5,6 \dagger}$, João Fernandes ${ }^{2}$, Patrício Costa ${ }^{5,6}$, Marianna Arvanitakis ${ }^{8}$, Arjun D. Koch ${ }^{9}$, Jan-Werner Poley ${ }^{9}$, Javier Jimenez ${ }^{10}$, Enrique Dominguez-Munõz ${ }^{11}$, Pietro Familiari ${ }^{12}$, Marco J. Bruno ${ }^{9}$ and Mário Dinis-Ribeiro 7,13

\begin{abstract}
Background: Existing proposed classification systems for the Papilla of Vater (PV) suboptimally account for all relevant, encountered PV appearances, are too complex or have not been assessed for intra- or interobserver variability. We proposed a novel endoscopic classification system for PV, determined its inter- and intraobserver rates and used the classification system to assess whether the success and complications of needle-knife fistulotomy (NKF) are influenced by the morphology of the PV.

Methods: The classification system was developed by expert endoscopists. To evaluate the inter- and intraobserver agreement, an online questionnaire was sent to 20 endoscopists from several countries (10 experts and 10 nonexperts) that included 50 images of papillae of Vater divided among various categories. Four weeks later, a second survey, with the images from the first questionnaire randomly reordered, was sent to the same endoscopists. The inter- and intraobserver agreements among the experts and nonexperts was calculated. Using the proposed classification system, all 361 consecutive patients who underwent NKF for biliary access to a naïve papilla were prospectively enrolled in the study.

Results: The novel classification system comprises 7 categories: type I, flat type, lacking an oral protrusion; type IIA, prominent tubular nonpleated type, with an oral protrusion and $<1$ transverse fold over the oral protrusion; type IIB, prominent tubular pleated type, with an oral protrusion and $>2$ transverse folds over the oral protrusion; type IIC: prominent bulging type, with an enlarged and bulging oral protrusion; type IIIA, diverticular-intradiverticular type, with a papillary orifice inside the diverticulum; type IIIB: diverticular-diverticular border type, with a papillary orifice less than $2 \mathrm{~cm}$ from the diverticular border; type IV: unclassified papilla, with no morphology classified in the other categories. The interobserver agreement between experts was substantial ( $K=0.611,95 \% \mathrm{Cl} 0.498-0.709)$ and was higher than that between nonexperts $(K=0.516 ; 95 \% \mathrm{Cl} 0.410-0.636)$. The intraobserver agreement was substantial
\end{abstract}

\footnotetext{
${ }^{*}$ Correspondence: jmtcanena@live.com.pt

†Jorge Canena and Luis Lopes have contributed equally to this study and

should be considered joint first authors.

1 Department of Gastroenterology, Professor Doutor Fernando Fonseca

Hospital, IC 19, 2720276 Amadora, Portugal

Full list of author information is available at the end of the article
}

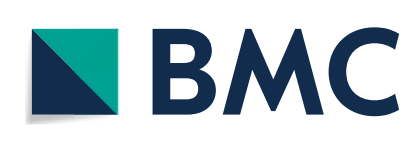

(c) The Author(s) 2021. Open Access This article is licensed under a Creative Commons Attribution 4.0 International License, which permits use, sharing, adaptation, distribution and reproduction in any medium or format, as long as you give appropriate credit to the original author(s) and the source, provide a link to the Creative Commons licence, and indicate if changes were made. The images or other third party material in this article are included in the article's Creative Commons licence, unless indicated otherwise in a credit line to the material. If material is not included in the article's Creative Commons licence and your intended use is not permitted by statutory regulation or exceeds the permitted use, you will need to obtain permission directly from the copyright holder. To view a copy of this licence, visit http://creativecommons.org/licenses/by/4.0/. The Creative Commons Public Domain Dedication waiver (http://creativeco $\mathrm{mmons}$.org/publicdomain/zero/1.0/) applies to the data made available in this article, unless otherwise stated in a credit line to the data. 
among both experts $(\mathrm{K}=0,651 ; 95 \% \mathrm{Cl} 0.586-0.715)$ and nonexperts ( $\mathrm{K}=0.646,95 \% \mathrm{Cl} 0.615-0.677)$. In a multivariate model, type IIIA and IIIB were the only independent risk factors for difficult rescue NKF biliary cannulation $(P=0.003$ and $P=0.019$, respectively), and type I and type IIB were the only independent risk factors for a prolonged cannulation time using NKF $(P<0.001$ and $P=0.005$, respectively).

Conclusions: The novel endoscopic classification system for PV is highly reproducible among experienced ERCPists according to the substantial level of agreement between experts. However, nonexperts require further training in its use. Using the novel classification system, we identified different types of papillae significantly associated with a lower efficacy of NKF and a prolonged time to obtain successful biliary cannulation using NKF.

\section{Introduction}

The success of therapeutic biliary Endoscopic Retrograde Cholangiopancreatography (ERCP) depends on selective biliary cannulation, which is the most important step of the procedure $[1,2]$. However, conventional techniques for gaining access into the biliary system may fail in $5-35 \%$ of cases [1-4]. Therefore, in the subset of patients that undergoes ERCP, there is a need for more advanced access techniques. Such a rescue strategy includes several procedures, namely, pancreatic guidewire-assisted biliary cannulation and precut biliary sphincterotomy. Several precut modalities are available, and one of these techniques, namely, needle-knife fistulotomy (NKF), is increasing in popularity. Previous studies have suggested that although overall cannulation rates were comparable between both precut techniques, the rate of post-ERCP pancreatitis (PEP) was significantly lower after NKF [58]. Therefore, the European Society of Gastrointestinal Endoscopy (ESGE) has recently recommended needleknife fistulotomy as the preferred technique for precutting [9]. Some authors have suggested that NKF should only be undertaken for papillae with a long intramural segment to avoid adverse events, namely, PEP and perforations [9-11]. Authors have argued that prominent papillae are not only easier to cut but also associated with larger common bile ducts (CBDs), not thin bile ducts, which have been suggested to be an independent risk factor for complications in patients subjected to rescue precut techniques $[2,12,13]$. However, a recent study has shown that the morphology of the papilla must not be used as a predictor of the diameter of the terminal $\mathrm{CBD}(\mathrm{t}-\mathrm{CBD})$, as there is no correlation between these two items [14]. Therefore, it is important to know if the macroscopic appearance of the major duodenal papilla influences the success of NKF and if endoscopists decision in undertaking NKF should be based on the morphology of the ampulla of Vater. Until now, no studies have addressed whether the success and complications of NKF are influenced by the endoscopic morphology of the major papilla.

The eponym "papilla of Vater" is derived from Abraham Vater, a German anatomist who first published a description of the papilla in 1720 [15]. In his original work, Vater recognized distinct variations in the anatomy of the ampulla among individuals [16]. The widespread use of high-quality digital images has led to various reports on the morphology of the major papilla, and there is a clear need and desire for an endoscopic classification system based on the morphology of the ampulla. During the last decade, several authors have proposed different classification systems and have used them to predict the success of cannulation, the rate of complications and the need for more advanced access techniques $[10,17-20]$. However, only one endoscopic classification system has been subjected to an inter- and intraobserver agreement study. Haraldsson et al. proposed an endoscopic classification system of 4 types of papillae [18]. Two years later, they reported, in a subsequent study, that the classification system was useful in predicting difficult biliary cannulation not only for experienced endoscopists but also for beginners [19]. However, other distinct morphological features were not taken into account in this classification system, as suggested in other reports [9, 17, 20]. Therefore, existing proposed classification systems suboptimally account for all relevant encountered papilla of Vater appearances, are too complex or have not been assessed for inter- or intraobserver variability. We conducted a study aiming to (a) devise a novel extended classification system for the papilla of Vater and assess the inter- and intraobserver agreement rates among endoscopists with different levels of expertise (expert versus nonexpert endoscopists) and (b) assess whether the success and complications of NKF are influenced by the morphology of the ampulla of Vater using our novel extended classification system of the major papilla.

\section{Methods \\ Study 1: A novel extended classification system for the ampulla of Vater Type of study, patients and endoscopists}

This study was divided into two parts: part 1 , in which the classification system was developed, and part 2 , in which the reproducibility of the novel extended classification system was evaluated. 
The study population comprised all patients with a naïve papilla who were referred for ERCP at Hospital Santa Luzia in Viana do Castelo, a hospital affiliated with the University of Minho. Under full duodenal inflation, a complete set of at least four pictures was taken and stored in a digital database. This study was conducted in compliance with the International Conference on Harmonization guidelines for Good Clinical Practice (E6) and the 2013 Declaration of Helsinki. All enrolled patients provided informed written consent before their procedures, and the Ethics Committee at our institution approved this study (ULSAM 47/2018-10/10).

\section{Part 1: development of the classification system}

The classification system was developed by expert endoscopists during a 6-month period, using a modified Delphi method to achieve consensus [21]. First, a set of 550 still images from our papilla major library database (all available images) were distributed among and reviewed by all endoscopists involved in part 1 . After a first meeting in which the main morphologic criteria were agreed upon, subsequent meetings took place to complete the classification system. The proposed morphologic criteria used in this classification system were (1) the shape of the papilla, (2) the protrusion of the oral segment of the papilla which was defined as the aspect of the intra-duodenal portion of the ampullary complex and its 'protrusion' into the duodenal lumen, (3) the number of transverse folds on the oral portion of the papilla, (4) the presence of a diverticulum, regardless of the oral protrusion of the ampullary complex and (5) the inclusion of a category named unclassified papilla to accommodate the remaining papillae. During the process of achieving consensus the shape of the papillary orifice and the ratio between the longitudinal measure versus the transverse measure of the papilla were consensually not included in the classification because it would transform the classification in a very complex system and therefore not suitable for routine clinical practice. A web-based platform was used for structured discussion and voting to refine the proposal. The final version of the classification system (Viana Classification) was voted on a working meeting held in the city of Viana do Castelo, on the northern coast of Portugal.

\section{Part 2: reliability of the classification system}

For the assessment of the inter- and intraobserver agreement rates among the endoscopists, we formed 2 groups: endoscopists with expertise in ERCP $(n=10)$ from different countries (Portugal, Belgium, Italy, Spain and the Netherlands) and a group of gastroenterology residents with limited experience in ERCP (less than one year of experience and less than 200 ERCPs performed/ monitored), required during the residency curriculum ( $n=10$; all Portuguese). Expertise with ERCP was defined as having performed more than 1000 ERCPs and having more than 6 years of experience. The endoscopists involved in part 1 did not participate in the agreement study. The reliability of the classification system was assessed using a web-based questionnaire with 50 still papilla images selected prospectively from our library after being classified. The images were randomly selected.

The survey started with a description of the classification system and some training questions followed by direct feedback for the respondents to become familiar with the classification system. Each question in the survey was accompanied by a large still image of an ampulla and presented on a single page, always with an explanatory picture of the classification system at the bottom. Respondents needed to make an obligatory choice from a dropdown box to identify the particular type, from the seven possible types, to which they categorized each image. All the participants had unlimited time to view each papilla or the complete set of papillae. Furthermore, they were allowed to return and change a previous decision on the type of papilla selected.

The questionnaire was distributed to 20 endoscopists (see above). Data from each endoscopist, in addition to their classification as experienced/trainee, were anonymized and entered directly into a database for later analysis. The participants were not able to record or keep a register of the answers from the first survey. One month after the completion of the first questionnaire, a second version of the survey was sent to the same endoscopists to evaluate intraobserver agreement. This second version was identical to the first version, except that the images were randomly reordered.

\section{Study 2: Influence of the novel extended classification system on the outcomes of NKF}

This was an observational multicenter study. Between May 2018 and October 2020, all consecutive patients who underwent NKF for biliary access to a naïve papilla were enrolled in the study and were followed prospectively (see below for endoscopists involved). The exclusion criteria were as follows: (1) patients with surgically altered anatomy, (2) patients with tumors of the papilla and (3) patients unable to be positioned prone or supine for cholangiography acquisition.

The collected data included patient demographics, indication for ERCP, underlying biliary pathology, therapeutic interventions, endoscopic morphology of the major papilla, length of time needed to achieve biliary cannulation after starting NKF, intraprocedure complications and postprocedure complications. This study was conducted at 3 institutions with a total annual load 
of 1300 ERCPs. This study was conducted in compliance with the International Conference on Harmonization guidelines for Good Clinical Practice (E6) and the 2013 Declaration of Helsinki. All of the patients provided informed written consent before their procedures. The Ethics Committee at each institution approved this observational study (EDOC/ULSBA/15,191, ULSAM 42/2019 and EC/59-2018).

\section{Endpoints and definitions for the study 2}

The primary endpoint was the influence of the endoscopic appearance of the major papilla on the success of NKF and adverse events. The secondary endpoint included the influence of the morphology of the ampulla on the time to achieve biliary cannulation and the technical success rate of NKF globally and at initial ERCP.

The $\mathrm{t}-\mathrm{CBD}$ diameter was assessed $1 \mathrm{~cm}$ above the distal end of the CBD on cholangiography, as described elsewhere [14]. Biliary pathology was divided into benign and malignant. The time needed to achieve biliary cannulation using NKF was defined as the length of time between the first contact with the papilla by a needleknife and visualization of a guidewire into the biliary duct. The adverse event rate was defined as the rate of procedure-related adverse events. Overall adverse events, namely, post-ERCP pancreatitis (PEP), ERCP bleeding and retroperitoneal perforation, were classified and graded according to consensus guidelines [7, 22, 23].

\section{Intervention, endoscopists and PEP prevention}

ERCP procedures were performed with patients in the prone position under sedation with propofol administered by an anesthesiologist. Before starting biliary cannulation, at least four still images of the papilla were taken at full inflation and stored in a digital database. The classification system was provided during the ERCP; retrospective classification of the papilla using videos or still images after ERCP was not possible. Patients without a classified papilla at initial ERCP were excluded. The endoscopists performing NKF in the study (JC, LL) have an annual load above 500 ERCPs/year and have achieved selective biliary cannulation in more than $80 \%$ of patients using standard access techniques. Both have performed more than 800 NKFs in their career and more than $80 \mathrm{NKFs} /$ year in the last 5 years. In the study period, NKF was performed early, which was defined as an NKF attempt after $5 \mathrm{~min}$ of unsuccessful attempts to achieve deep biliary cannulation using standard methods. The NFK technique has been described extensively elsewhere $[1-4,6,9,17,24,25]$.

All patients underwent routine rectal administration of $100 \mathrm{mg}$ of diclofenac or indomethacin immediately before ERCP. In all cases involving pancreatic opacification or guidewire passage into the pancreatic duct, prophylactic pancreatic stenting was performed according to known guidelines $[9,26]$.

\section{Statistical analysis \\ Study 1: A novel extended classification system for the ampulla of Vater}

The inter- and intraobserver agreement was calculated for the entire group, and a subanalysis was subsequently performed by dividing the endoscopists into two groups according to their experience. Intraobserver agreement was calculated by comparing the answers from the same endoscopist from the two surveys. The degree of agreement between the answers of the endoscopists was assessed using Fleiss' kappa statistics for unordered categories as follows: $k$ between 0.01 and 0.2 , slight; $K$ between 0.21 and 0.4 , fair; $K$ between 0.41 and 0.6 , moderate; $\mathrm{K}$ between 0.61 and 0.8 , substantial; and $\mathrm{K}$ between 0.81 and 1.0, almost perfect agreement [27]. The proportion of agreement with the reference, the predefined classification system, was evaluated using relative frequencies against the observed responses by the 20 endoscopists surveyed.

\section{Study 2: Influence of the novel extended classification system on the outcomes of NKF}

Qualitative variables are summarized using absolute and relative frequencies, and quantitative variables are summarized using the mean and standard deviation or the median and range, depending on their distribution profiles. The normality of the quantitative variables was assessed using a histogram of the distribution of the variables.

Differences between categorical variables were tested using the chi-square test and Fisher's exact test.

To explain successful biliary cannulation in the initial ERCP, qualitative binary regression models with logit specification were defined. The average marginal effects, standard errors and individual significance tests are presented in tables. To explain the overall cannulation time, a multiple linear regression model was defined using ordinary least squares (OLS) to estimate the coefficients. In the multivariate model, distal malignant stricture was one of the variables used in the analysis.

The null hypothesis was rejected when the test statistic $\mathrm{p}$-values were less than $<0.05$. Statistical analysis was performed and graphics were generated using Stata software (StataCorp. 2015. Stata Statistical Software: Release 14. College Station, TX: StataCorp LP). 


\section{Results}

Study 1: A novel extended classification system for the ampulla of Vater The classification system

The proposed classification system includes 7 categories: type I: flat type, without an oral protrusion; type IIA: prominent tubular nonpleated type, with an oral protrusion and $<1$ transverse fold over the oral protrusion; type IIB: prominent tubular pleated type, with an oral protrusion and $>2$ transverse folds over the oral protrusion; type IIC: prominent bulging type, with an enlarged and bulging oral protrusion; type IIIA: diverticular-intradiverticular type, with a papillary orifice inside the diverticulum; type IIIB, diverticular-diverticular border type, with a papillary orifice less than $2 \mathrm{~cm}$ from the diverticular border; type IV: unclassified papilla, a type of papilla with no morphology classified into the other categories (Fig. 1).

\section{Reliability}

All questionnaires were completed by the 20 endoscopists. The questionnaire contained examples of 8 type I papillae, 8 type IIA papillae, 8 type IIB papillae, 8 type IIC papillae, 6 type IIIA papillae, 6 type IIIB papillae and 6 type IV papillae.

The overall interobserver agreement was moderate $(\mathrm{K}=0.567)$ (Table 1$)$. When subanalysis was performed according to group, the level of agreement was substantial for the experts $(K=0.611)$ and moderate for the trainees $(K=0.516)$. The overall intraobserver agreement was substantial for both the experts $(K=0.651)$ and nonexperts $(K=0.646)$.

The rate of agreement among the 20 endoscopists was $71.85 \%$ and varied according to papilla type (range 40-90\%) (Fig. 2). Type I papillae (flat type), type IIC papillae (bulging type) and type IIIA papillae (intradiverticular type) had a high level of concordance. The level of agreement was lower for type IIA (prominent nonpleated type) and type IIB (prominent pleated type) papillae, with $67 \%$ and $64 \%$ concordance, respectively. The category with the least agreement was the unclassified papilla (type IV) with $40 \%$ concordance. The rate of agreement between experts and nonexperts was similar except for type IIA (prominent tubular nonpleated type) papillae, in which the rate of agreement between experts and trainees was substantially different (52\% vs $67 \%)$.

A more detailed examination of the distribution of answers of the endoscopists revealed that there was an interchangeability of choices between type IIA and Type IIB, and most of the endoscopists that did not consider type IV instead selected type I in such cases (Table 2).
Study 2: Influence of the novel extended classification system on the outcomes of NKF

Patients

During the study period, namely, 2639 naïve papillae were subjected to ERCP. Of these patients, 361 underwent NKF as a rescue method for biliary cannulation early, namely, after five minutes of biliary cannulation attempts using standard techniques. Therefore, 361 patients (156 males and 205 females), with a mean age of 69.6 years (range 18-97 years), were enrolled in the study. Classification of the papilla into the predefined types was possible for all patients. The distribution of the different papillae is shown in Fig. 3 and Table 3. Type IIA (prominent tubular nonpleated type) was the most frequent (128 patients, 35.4\%), followed by type IIB (prominent tubular pleated type), which was found in 109 patients (30.2\%). Patient demographics, group distribution and group characteristics are summarized in Table 3.

\section{Influence of the endoscopic appearance of the major papilla on the success of NKF and adverse events}

Overall, regarding the initial cannulation rate, selective biliary cannulation was obtained in 334/361 (92.5\%) of the patients. The initial cannulation rate using NKF was significantly different between the different types of papillae (Table 4 and Fig. 2). Type IIB (prominent tubular pleated type), type IIIA (diverticular-intradiverticular type) and type IIIB (diverticular-diverticular border type) were associated with the lowest cannulation rates using NKF. In the multivariate model (Table 5), type IIIA and IIIB were the only independent risk factors for difficult biliary cannulation (odds ratio: 0,567; 95\% confidence interval $0.008-0384, P=0.003$ and odds ratio: 0,$081 ; 95 \%$ confidence interval 0.009-0.656, $P=0.019$, respectively). Overall biliary cannulation was obtained at the second attempt in $351 / 361$ patients $(97.22 \%)$. There were no significant differences in the cannulation rate between the different types of papillae when using NKF at the second attempt.

The cannulation time using NKF was significantly different among the different types of papillae, with type I, type IIB and type IIIB being associated with the longest cannulation times when using NKF. However, in the multivariate regression model (Table 6), type I and type IIB were the only independent risk factors for a prolonged cannulation time using NKF (odds ratio: 8,266; 95\% confidence interval 4,077-12.453, $P<0.001$ and odds ratio: 3.593; 95\% confidence interval 1.114-6.071, $P=0.005$, respectively).

In total, procedure-related adverse events (Table 4) were observed in $27 / 361$ of the patients $(7.5 \%)$. The rate of adverse events was not significantly different 


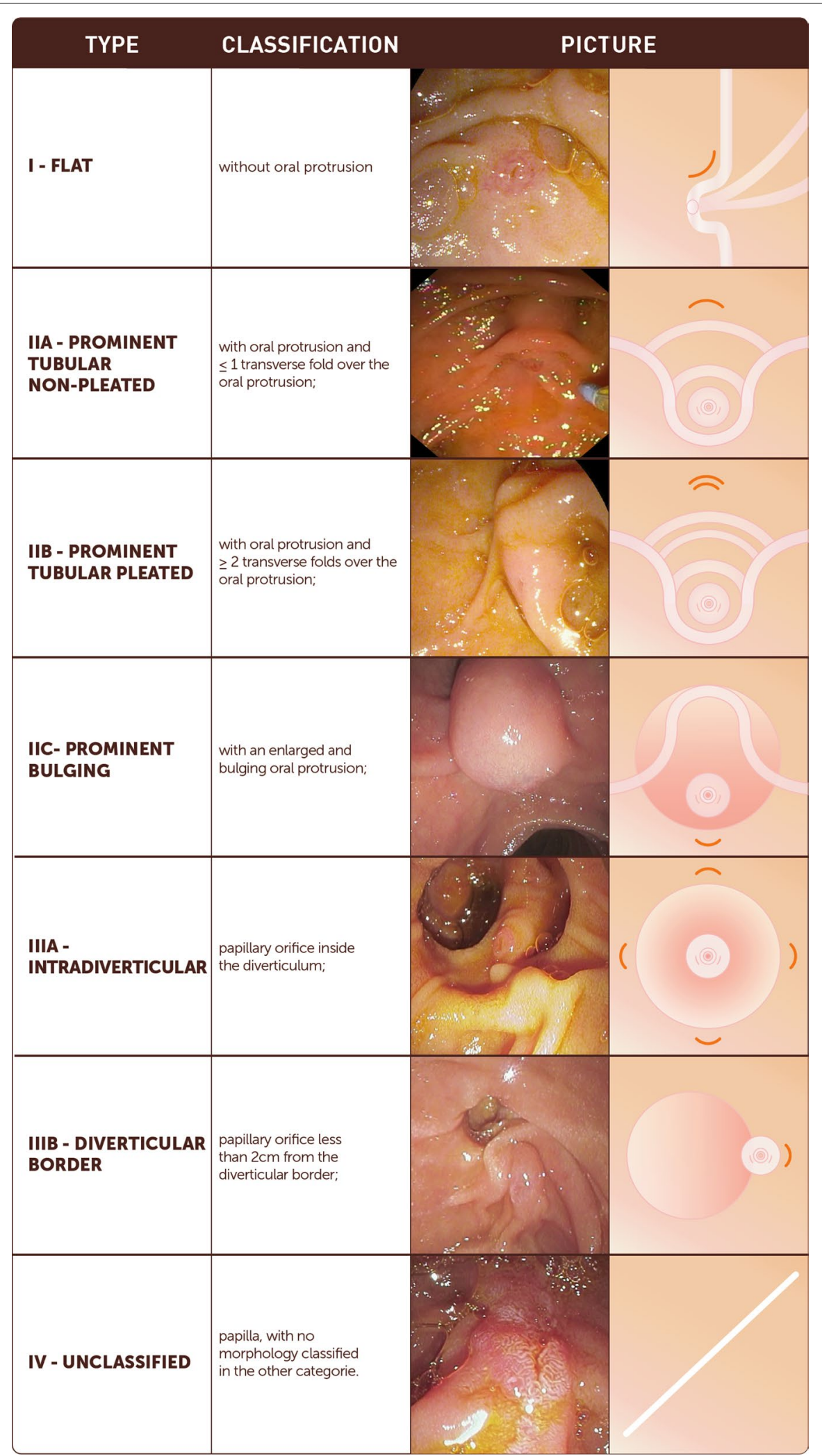

Fig. 1 Novel classification of the endoscopic appearance of the papilla of Vater 
Table 1 Interobserver and intraobserver agreement among experts and nonexperts

\begin{tabular}{lcl}
\hline Intraobserver agreement & $\mathrm{K}(95 \% \mathrm{Cl})$ & Agreement \\
\hline All endoscopists & $0.648(0.641-0.656)$ & Substantial \\
Experts & $0.611(0.498-0.709)$ & Substantial \\
Trainees & $0.516(0.410-0.636)$ & Substantial \\
Interbserver agreement & & \\
All endoscopists & $0.567(0.470-0.675)$ & Moderate \\
Experts & $0.651(0.586-0.715)$ & Substantial \\
Trainees & $0.646(0.615-0.677)$ & Moderate \\
\hline
\end{tabular}

among the different types of papillae. Overall, the most common adverse event, pancreatitis, was observed in $18 / 361$ of the patients $(4.9 \%)$.

\section{Discussion}

In this study, a novel extended endoscopic classification system of the major papilla was proposed. The interobserver agreement was substantial among the expert participants and moderate among the group of nonexperienced endoscopists. The results were highly reproducible by all endoscopists based on the substantial intraobserver agreement among the expert and nonexpert participants. Furthermore, using the new classification system, we identified different types of papillae significantly associated with a lower efficacy of NKF and a prolonged time to obtain successful biliary cannulation using NKF.

Previous studies have been undertaken to devise a classification system for the major papilla. In 2007, Horiuchi et al. classified the major papilla based on the size of the oral protrusion into the duodenal lumen into small, large or swollen [9]. The authors suggested that this classification system could be used to guide the type of precut sphincterotomy performed for patients

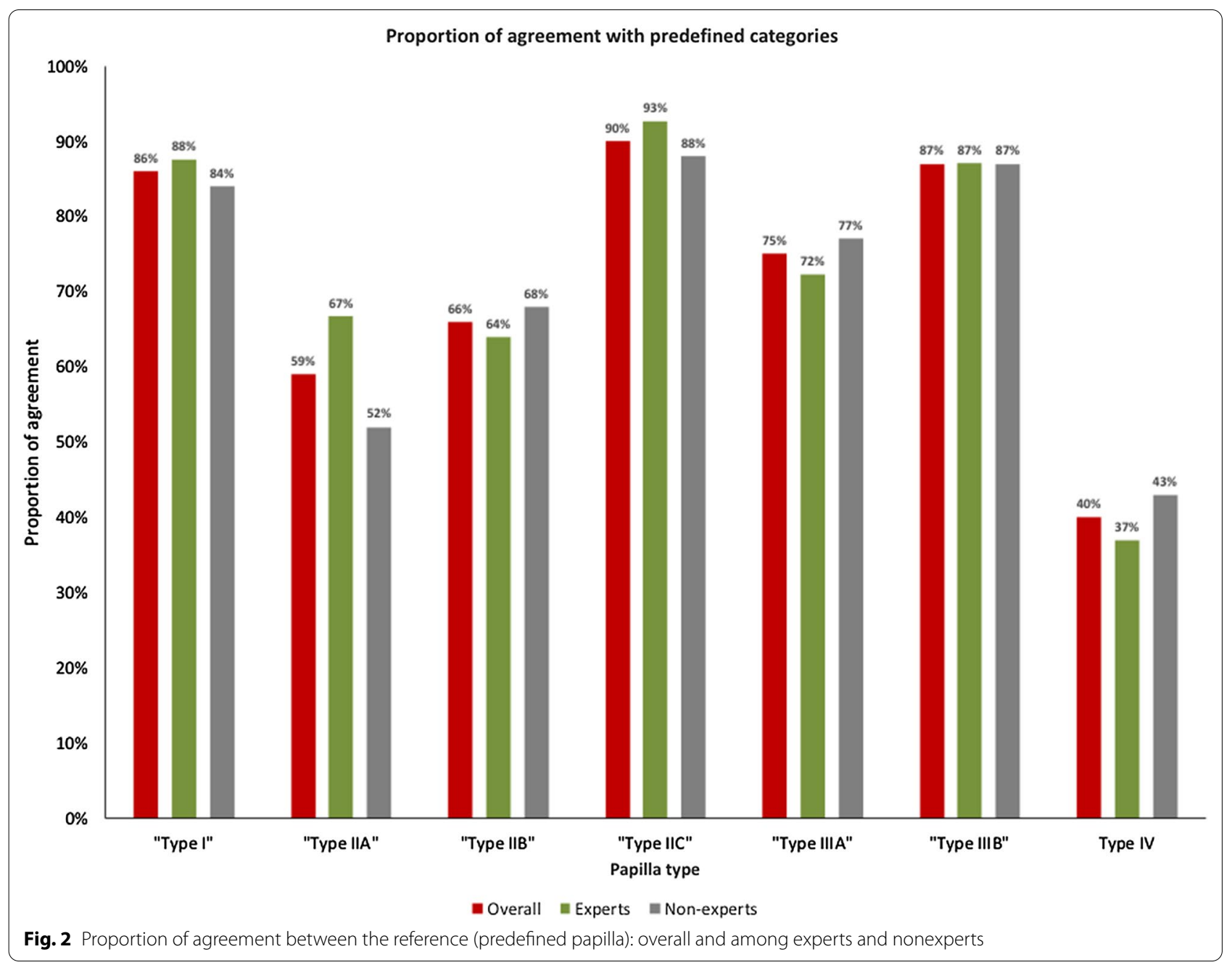


Table 2 Proportion of agreement between the reference (predefined papilla) and the survey responses for each type of papilla

\begin{tabular}{|c|c|c|c|c|c|c|c|}
\hline \multirow{2}{*}{$\begin{array}{l}\text { Classification } \\
\text { proposed }\end{array}$} & \multicolumn{7}{|c|}{ Survey responses by the 20 endoscopists } \\
\hline & Type I (\%) & Type IIA (\%) & Type IIB (\%) & Type IIC (\%) & Type IIIA (\%) & Type IIIB (\%) & Type IV (\%) \\
\hline Type I & 86 & 2.5 & 1.5 & 0 & 0 & 0 & 12 \\
\hline Type IIA & 4 & 59 & 31 & 4 & 0 & 0 & 2 \\
\hline Type IIB & 0 & 24 & 66 & 10 & 0 & 0 & 0 \\
\hline Type IIC & 0 & 0 & 9 & 90 & 0 & 0 & 1 \\
\hline Type IIIA & 3.5 & 0 & 0 & 0 & 75 & 15 & 6.5 \\
\hline Type IIIB & 0.5 & 8 & 2 & 0 & 2 & 87 & 0.5 \\
\hline Type IV & 47 & 0 & 2 & 0 & 9 & 2 & 40 \\
\hline
\end{tabular}

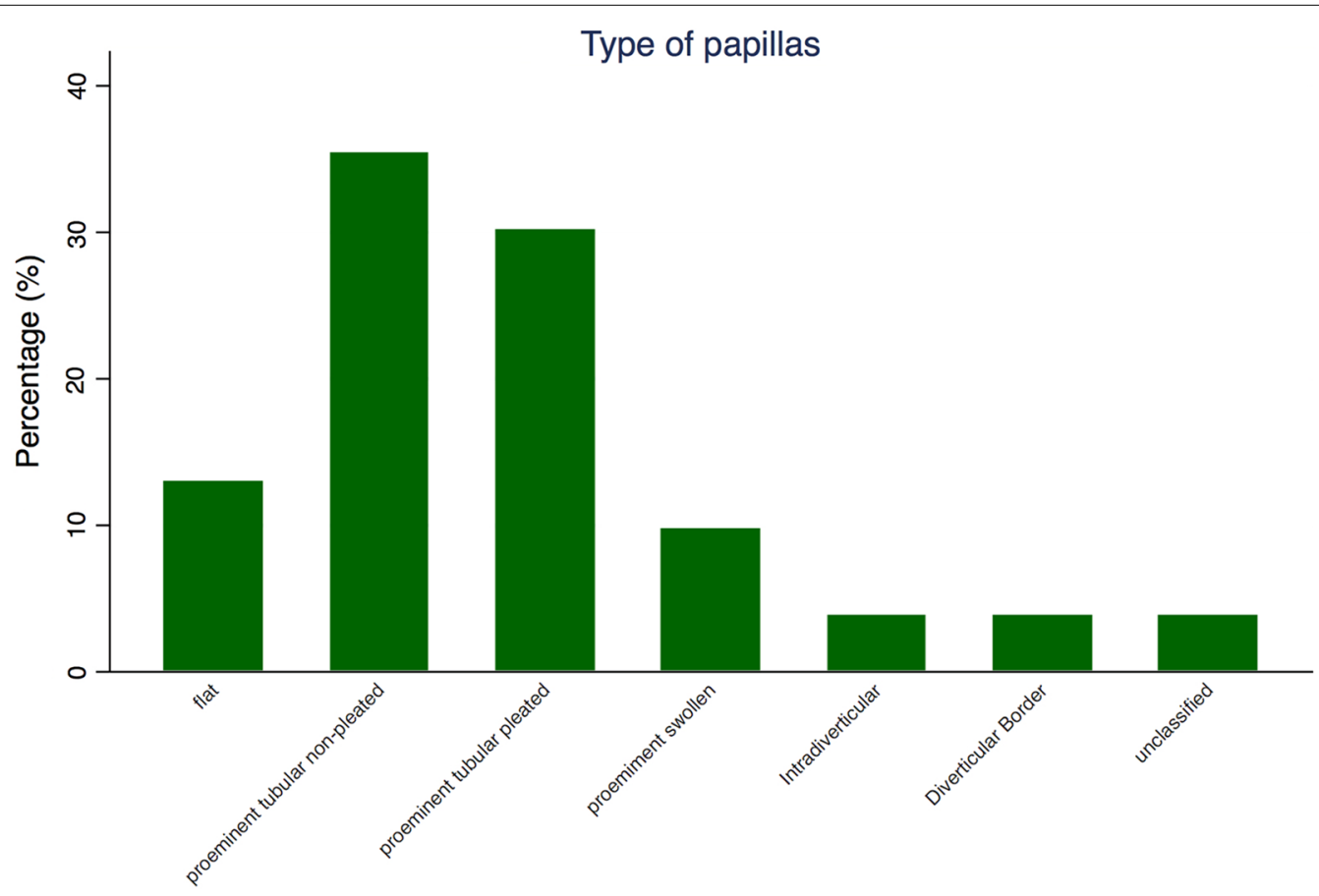

Fig. 3 Distribution of the different types of papillae among 361 patients

Table 3 Patient's demographics, group distribution and group characteristics of 361 patients submitted to NKF

\begin{tabular}{|c|c|c|c|c|c|c|c|c|}
\hline & $\begin{array}{l}\text { Type I } \\
\text { n (\%) } \\
47(13.0)\end{array}$ & $\begin{array}{l}\text { Type lla } \\
\text { n (\%) } \\
128(35.5)\end{array}$ & $\begin{array}{l}\text { Type Illb } \\
\text { n (\%) } \\
109(30.2)\end{array}$ & $\begin{array}{l}\text { Type Ilc } \\
\text { n (\%) } \\
35(9.6)\end{array}$ & $\begin{array}{l}\text { Type Illa } \\
\text { n (\%) } \\
14(3.9)\end{array}$ & $\begin{array}{l}\text { Type Illb } \\
\text { n (\%) } \\
14(3.9)\end{array}$ & $\begin{array}{l}\text { Type IV } \\
\text { n (\%) } \\
14(3.9)\end{array}$ & $p$ \\
\hline Age, median & 74 & 70 & 72 & 74 & 79 & 80 & 75 & 0.074 \\
\hline Sex, n (\%) & & & & & & & & 0.528 \\
\hline Male & $24(51)$ & $55(43)$ & $49(45)$ & $15(43)$ & $4(29)$ & $3(21)$ & $6(43)$ & \\
\hline Female & $23(49)$ & $73(57)$ & $60(55)$ & $20(57)$ & $10(71)$ & $11(79)$ & $8(57)$ & \\
\hline \multicolumn{9}{|l|}{ Final diagnosis, n (\%) } \\
\hline CBD stones & $23(48.9)$ & $83(64.9)$ & $51(46.8)$ & $20(57.1)$ & $11(78.6)$ & $7(50.0)$ & $3(21.4)$ & 0.010 \\
\hline Malignant stricture & $16(34.0)$ & $22(17.2)$ & $26(23.9)$ & $7(20)$ & $1(7.1)$ & $1(7.1)$ & $5(35.7)$ & 0.229 \\
\hline Leaks & $1(2.1)$ & $3(2.3)$ & $5(4.6)$ & $1(2.9)$ & 0 & 0 & 0 & 0.935 \\
\hline Other findings & $7(15.0)$ & $20(15.6)$ & $27(24.8)$ & $7(20.0)$ & $2(14.3)$ & $6(42.9)$ & $6(42.9)$ & 0.356 \\
\hline
\end{tabular}


Table 4 Influence of the endoscopic appearance of the major papilla on the success of NKF and adverse events in 361 patients

\begin{tabular}{|c|c|c|c|c|c|c|c|c|}
\hline & $\begin{array}{l}\text { Type I } \\
\text { n (\%) } \\
47(13.0)\end{array}$ & $\begin{array}{l}\text { Type lla } \\
\text { n (\%) } \\
128(35.5)\end{array}$ & $\begin{array}{l}\text { Type Ilb } \\
\text { n (\%) } \\
109(30.2)\end{array}$ & $\begin{array}{l}\text { Type IIc } \\
\text { n (\%) } \\
35(9.6)\end{array}$ & $\begin{array}{l}\text { Type Illa } \\
\text { n (\%) } \\
14(3.9)\end{array}$ & $\begin{array}{l}\text { Type Illb } \\
\text { n (\%) } \\
14(3.9)\end{array}$ & $\begin{array}{l}\text { Type IV } \\
\text { n (\%) } \\
14(3.9)\end{array}$ & $p$ \\
\hline \multicolumn{9}{|l|}{ Biliary cannulation, n (\%) } \\
\hline Success in first ERCP & 44 (93.6) & $124(96.9)$ & $100(91.7)$ & $35(100)$ & $9(64.3)$ & $10(71.4)$ & $12(85.7)$ & 0.000 \\
\hline Overall biliary cannulation & $46(97.9)$ & $127(99.2)$ & $105(96.3)$ & $35(100)$ & $13(92.9)$ & $12(85.7)$ & $13(92.9)$ & 0.041 \\
\hline $\begin{array}{l}\text { Cannulation time (mins), } \\
\text { median (p25-p75) }\end{array}$ & $14.3(7-26)$ & $5.0(1-38)$ & $8.8(7-15)$ & $5.5(3-12)$ & $8.0(7-10)$ & $9.5(5-14)$ & $8.7(5-21)$ & 0.0001 \\
\hline \multicolumn{9}{|l|}{ Adverse events, $n$ (\%) } \\
\hline Overal & $5(10.6)$ & $7(5.5)$ & $10(9.2)$ & $3(8.6)$ & 0 & $2(14.3)$ & 0 & 0.549 \\
\hline Pancreatitis & $4(8.5)$ & $5(3.9)$ & $5(4.6)$ & $2(5.7)$ & 0 & $2(14.3)$ & 0 & 0.488 \\
\hline Bleeding & $1(2.1)$ & $2(1.6)$ & $5(4.6)$ & $1(2.9)$ & 0 & 0 & 0 & 0.837 \\
\hline Perforation & 0 & 0 & 0 & 0 & 0 & 0 & 0 & - \\
\hline
\end{tabular}

NKF, needle knife fistulotomy

Table 5 Results of a multivariate logistic regression model to evaluate predictors of successful biliary cannulation in 361 observations

\begin{tabular}{lllrl}
\hline & OR & $p$ & \multicolumn{2}{c}{$95 \% \mathrm{Cl}$} \\
\cline { 4 - 5 } & & & Lower & Upper \\
\hline Sex & 1.903 & 0.2330 & -0.521 & 9.949 \\
Age & 1.009 & 0.668 & 0.967 & 1.053 \\
Viana classification & & & & \\
I & 1.321 & 0.361 & 0.109 & 2.235 \\
Ila & 0 & & & \\
IIb & 0.495 & 0.361 & 0.109 & 2.235 \\
IIC & 1.103 & 0.458 & 1.002 & 2.236 \\
IIla & 0.567 & $0.003^{*}$ & 0.008 & 0.384 \\
IIIb & 0.081 & $0.019^{*}$ & 0.009 & 0.656 \\
IV & 0.981 & 0.582 & 0.123 & 1.026 \\
Biliary stenosis & 0.633 & 0.489 & 0.173 & 2.307 \\
CBD diameter & 1.090 & 0.204 & 0.953 & 1.247 \\
\hline${ }^{*} p<0.01$ & & & &
\end{tabular}

with a difficult biliary cannulation. The authors concluded that NKF had the highest success rate when performed for swollen papillae, which is similar to our type IIC. However, this classification system was not validated, and the definition of a difficult cannulation as used in that study was arbitrary and has not been used by most other authors or guidelines. Several years later, Lee et al. described four types of papillae: nonprominent, prominent, bulging and a fourth type called the distorted type [17]. In their original report, the authors used this classification system to evaluate the success and safety of precut fistulotomy for difficult biliary cannulation as performed by endoscopists with a low level of training. The authors reported that the success of
Table 6 Results of a multiple regression model to evaluate predictors of cannulation time

\begin{tabular}{llllr}
\hline & Coef & $p$ & \multicolumn{2}{l}{$95 \% \mathrm{Cl}$} \\
\cline { 3 - 5 } & & & Lower & Upper \\
\hline Sex & 1.326 & 0.208 & -0.742 & 3.394 \\
Age & 0.031 & 0.234 & -0.020 & 0.082 \\
Viana classification & & & & \\
I & 8.266 & $0.000^{*}$ & 4.077 & 12.453 \\
IIa & 0 & & & \\
IIb & 3.593 & $0.005^{*}$ & 1.114 & 6.071 \\
IIC & 1.237 & 0.466 & -2.100 & 4.573 \\
IIIla & 2.235 & 0.327 & -2.245 & 6.715 \\
IIIb & 1.157 & 0.468 & -1.979 & 4.294 \\
IV & 8.331 & 0.072 & -0.747 & 17.411 \\
Biliary stenosis & 2.591 & 0.063 & 1.960 & 3.220 \\
CBD diameter & -0.143 & 0.319 & -0.426 & 0.139 \\
\hline
\end{tabular}

${ }^{*} p<0.01 ; R$ squared $=0186$

NKF was similar between prominent and nonprominent papillae, but bulging papillae had a high rate of success of biliary cannulation using NKF (96.8\%). However, this classification system did not go through a validation process, and the definition used for a difficult biliary cannulation was a personal definition that is not used in other reports or guidelines on the subject. In short, the first two attempts to classify the major papilla used the morphological characteristics of the ampulla to guide the success of NKF. Therefore, it is important to know if a novel classification of the major duodenal papilla influences the decision to undertake NKF and if it is associated with adverse events. In 2016, a Scandinavian group proposed a new classification system, reporting 4 types of papillae: type 1 , regular; type 2 , 
small; type 3 , protruding or pendulous; and type 4, creased or rigid [18]. This classification system was evaluated with an inter- and intraobserver agreement study among 18 endoscopists (nine experts and nine nonexperts) using a set of 50 still images. The overall interobserver agreement was substantial $(\mathrm{K}=0.62)$ and similar between the experts $(\mathrm{K}=0.63)$ and nonexperts $(\mathrm{K}=0.61)$. Furthermore, the intraobserver agreement was also substantial $(K=0.66)$ and was again similar between the experts $(K=0.68)$ and nonexperts $(K=0.62)$. Two years later, the same group reported the relevance of using this classification system to assess the difficulty of bile duct cannulation [19]. They reported that type 2 and type 3 papillae were more frequently difficult to cannulate and that cannulation might even fail more frequently if a beginner starts it. However, despite the merit of this work, this classification system seemed incomplete immediately and did not recognize other morphological forms. Therefore, in 2019, a group from Japan proposed a novel classification system based on (1) the ratio of the length between the oral protrusion and the transverse diameter of the papilla (protrusion pattern) and (2) the papilla pattern, which indicates the surface pattern of the papilla, including the morphology of the orifice [20]. They proposed 8 types of papillae based on the ratio of the length of oral protrusion to the transverse diameter of the papilla, with an additional 5 types of papilla patterns. They subjected this proposed classification system to an internal validation method in which 3 experienced endoscopists agreed on the classification system. The manuscript did not specify if this validation was performed using still images and if the evaluators were the same as the original authors of the classification system, creating a large bias immediately in terms of the validation. Using this classification system, the authors reported that papillae with large protrusions represented an independent risk factor for a difficult cannulation. Despite the merits and efforts of the authors, this classification system was not tested for inter- and intraobserver agreement, and the classification system is of such complexity that it does not seem suitable for routine clinical practice. At present, the Nordic classification system is the only one suitable for use in routine practice. However, this system may have missed relevant macroscopic appearances of the ampulla of Vater, and there are several limitations that should be taken into account. Type 3 in the Nordic classification system includes all protruding papillae and does not include a necessary division between different types of protrusions into the lumen. Protruding papillae can assume different forms, namely, with several pleats and bulging. Therefore, we believe that prominent papillae should be divided into 3 groups: nonpleated, pleated and bulging, which intuitively are associated with distinct and different difficulties of cannulation when using not only standard techniques but also distinct advanced assessment techniques, potentially leading to differential risks and types of complications. All experienced endoscopists known from practice that prominent papillae with several folds do not represent an easy task for cannulation, especially without the use of any advanced access techniques. Papillae with more pleats (Type IIB) tend to have a longer intraduodenal portion of the common bile duct, several pleats and most of the time the orifice is hanging down into the duodenal lumen. Many times, these papillae are under overlying folds and deep cannulation is not generally easy. All experimented endoscopists have intuitively the idea that these papillae could be challenging. In current study Type IIB was associated with the lower levels of deep biliary cannulation (only Type III-the diverticular papillae performed poorly) and furthermore Type IIB was in independent risk factor for prolonged cannulation type. In future studies which are on their way and are the next step we will evaluate the performance of Type IIB when using traditional methods of cannulation. Recently, Adler [35] remembered that papillae under multiple draping, overlying folds (sometimes humorously referred to as the Shar-Pei dog papilla) should be taken into account in a classification system (our tubular pleated type). Additionally, true bulging papillae are challenging to cannulate with standard techniques and are probably better cannulated by precut techniques, namely, needle-knife suprapapillary fistulotomy [7, 17, 28-31]. Furthermore, the Nordic classification system does not include diverticular papillae, which have been associated with difficult cannulation and may be different from intradiverticular or papillae located on the edge (border) of the diverticulum. Most of the ERCPists report that ERCP for intradiverticular papillae continues to be a challenge [32-34], but no large series have yet to prove this statement, and it is clear that a new classification system that objectifies cannulation difficulty should include this type of papillae as strongly suggested by a recent paper from a well-known ERCPist [35]. Another possible conflicting issue with the work of Haraldsson et al. is their type 1 papilla (regular), which has no clear definition and therefore is not easy to classify during endoscopic visualization. Instead of regular papilla, we included a type IV papilla to include all possible variations in papillary morphologies, which we named unclassified papilla to accommodate other, less frequent endoscopic appearances of the ampulla and those that are impossible to classify. Finally, and 
accordingly with previous classification systems, small papillae (our flat type) have been associated with difficult cannulation and complications and should be included in any classification system of the major papilla [7, 10]. Therefore, and due to the limited morphological appearances available in the classification system from Haraldsson et al., we proposed a novel, extended classification system that accommodates an extended number of distinct features related to the endoscopic appearance of the papilla of Vater. Not surprisingly, a recent editorial suggested that classification systems with more types were strongly needed [35].

In this study, trainees had a poorer intraobserver agreement than experienced ERCPists, suggesting that papilla evaluation is easier for endoscopists who are used to examine papillae in daily practice. We observed a high level of concordance for the flat type, bulging type and diverticular type, suggesting that these types of papillae are easy to learn and differentiate. However, prominent papillae were more difficult to classify, namely, the difference between pleated and nonpleated papillae, due to the nature and number of pleats, and this difficulty was more pronounced for the nonexpert group. In fact, this was the only major difference between the answers of the experts versus nonexperts and the main reason why the interobserver rate was poorer in the trainee group. We believe that with training, endoscopists will be able to differentiate easily between the two types of papillae. Furthermore, we intuitively believe that these two types of papillae will behave differently in terms of cannulation difficulty, complications and precut techniques. Finally, the category of unclassified papilla had the poorest results with a low level of agreement. This may have resulted from the need of the endoscopist to classify an unexpected morphology into something else that was more common, namely, flat papillae, which more frequently can be confounded with the unclassified papilla category.

In this study, it is clear that flat papillae and all types of prominent papillae can be subjected to NKF with a success above $90 \%$ when performed by experienced endoscopists. Furthermore, diverticular papillae were the only independent risk factor for using NKF, and it is clear that this type of papillae should be addressed with a novel classification. Interestingly, diverticular papillae were not associated with a significantly longer duration for performing a successful NKF. This observation was associated with flat and tubular pleated papillae. These two types of papillae, one small and the other with a long intraduodenal portion of the common bile duct under multiple folds, are challenging to treat with NKF and therefore are associated with long times to achieve successful biliary cannulation.
Future studies will hopefully prove whether this classification system is easy to use in daily practice and consistently reproduced by all endoscopists. Furthermore, future studies should address the utility of this classification system in predicting the difficulty of cannulation using conventional techniques, complications, and which types of papillae are most suitable in each differential stage of the training process for novice ERCPists.

The present study has several limitations. First, we used still images instead of video sequences, which may only represent part of the morphological appearance of the ampulla. Another potential limitation is the use of Fleiss' kappa statistic, which while appropriate for testing whether agreement exceeds chance, has some limitations, as it makes no distinction among various types and sources of disagreement. Because it is affected by prevalence, it may not be appropriate to compare kappa between different studies or populations. Nonetheless, kappa can provide more information than a simple calculation of the raw proportion of agreement [36].

The strengths of our study include the extension of previous classification systems, attempting to accommodate a larger number of papilla morphologies that were not considered in previous studies, the number of endoscopists included and the inclusion of experts from different countries. Furthermore, we used this novel classification system to observe that different types of papillae were associated with different success rates of biliary cannulation and different times for successfully performing NKF using the largest series of NKF ever reported.

\section{Conclusion}

Our novel classification system for appraising the endoscopic appearance of the papilla of Vater is highly reproducible among experienced ERCPists based on a substantial level of agreement between experts. Although the results of the survey were consistently reproduced by all endoscopists, nonexperts will require further training in its use. Using this novel classification system, we observed that intradiverticular papillae were independent risk factors for difficult cannulation using NKF and flat and tubular pleated papillae were independent risk factors for a prolonged cannulation time using NKF. Future studies will need to demonstrate whether this extended novel classification system has clinical utility in terms of actually being able to prospectively predict cannulation difficulty with standard techniques and complication risks. Furthermore, this novel classification system would be a guide to selecting the most optimal biliary cannulation option for each patient though the subsequent clinical verification process. 


\begin{abstract}
Abbreviations
PV: Papilla of Vater; NKF: Needle-knife fistulotomy; ERCP: Endoscopic retrograde cholangiopancreatography; ESGE: European Society of Gastrointestina Endoscopy; PEP: Post-ERCP pancreatitis; t-CBD: Diameter of the terminal CBD.
\end{abstract}

\section{Authors' contributions}

Conception and design of the study, collection of data, analysis and interpretation of data, and drafting the manuscript: Luis Lopes; Conception and design of the study, collection of data, analysis and interpretation of data, and drafting the manuscript: Jorge Canena; conception and design of the study, collection of data, critical revision of the manuscript and approval of the final draft submitted: João Fernandes; statistical analysis, critical revision of the manuscript and approval of the final draft submitted: Patricio Costa; participation on the survey, critical revision of the manuscript and approval of the final draft submitted: Mariana Arvanitakis; participation on the survey, critical revision of the manuscript and approval of the final draft submitted: Arjun D. Koch; participation on the survey, critical revision of the manuscript and approval of the final draft submitted: Jan-Werner Poley; participation on the survey, critical revision of the manuscript and approval of the final draft submitted: Javier Jimenez; participation on the survey, critical revision of the manuscript and approval of the final draft submitted: Enrique DominguezMunõz; participation on the survey, critical revision of the manuscript and approval of the final draft submitted: Marc J. Bruno; participation on the survey the study, critical revision of the manuscript and approval of the final draft submitted: Pietro Familiari; critical revision of the manuscript and approval of the final draft submitted: Mário Dinis-Ribeiro. All authors read and approved the final manuscript.

\section{Availability of data and materials}

The datasets generated and/or analyzed in the present study are available from the corresponding author on reasonable request.

\section{Declarations}

\section{Ethics approval and consent to participate}

This manuscript included two studies, both observational. The two studies were conducted in compliance with the International Conference on Harmonization guidelines for Good Clinical Practice (E6) and the 2013 Declaration of Helsinki. All patients provided written informed consent before inclusion in the two studies. The study 1 -A novel extended classification system for the ampulla of Vater was approved by local Ethics Committee at Hospital de Santa Luzia (ULSAM 47/2018-10/10). The study 2, Influence of the novel extended classification system on the outcomes of NKF, which was multicenter, was approved in 3 different centers: (Beja Hospital_EDOC/ULSBA/15191; Santa Luzia Hospital ULSAM 42/2019 and Amadora-Sintra Hospital EC/59-2018).

\section{Consent for publication}

Not applicable.

\section{Competing interests}

The authors declare that they have no competing interests.

\footnotetext{
Author details

1 Department of Gastroenterology, Professor Doutor Fernando Fonseca Hospital, IC 19, 2720276 Amadora, Portugal. ${ }^{2}$ Department of Gastroenterology, Santa Luzia Hospital - Unidade Local de Saúde Alto Minho, Viana do Castelo, Portugal. ${ }^{3}$ Department of Gastroenterology, Nova Medical School/Faculty of Medical Sciences, Lisbon, Portugal. ${ }^{4}$ University Center of Gastroenterology, Hospital Cuf Tejo, Lisbon, Portugal. ${ }^{5}$ Life and Health Sciences Research Institute (ICVS), School of Medicine, University of Minho, Braga, Portugal. ${ }^{6}$ ICVS/3B's - PT Government Associate Laboratory, Braga/Guimarães, Portugal. ${ }^{7}$ Cintesis - Center for Health Technology and Services Research, Porto, Portugal. ${ }^{8}$ Department of Gastroenterology, Hepatology and Digestive Oncology, Erasme University Hospital Université Libre de Bruxelles, Brussels, Belgium. ${ }^{9}$ Department of Gastroenterology and Hepatology, Erasmus MC Cancer Institute, University Medical Center, Rotterdam, The Netherlands. ${ }^{10}$ Endoscopy Unit. Hospital Marques de Valdecilla, Santander, Spain. ${ }^{11}$ Gastroenterology Department, University Hospital of Santiago de Compostela, Santiago de Compostela, Spain. ${ }^{12}$ Digestive Endoscopy Unit, Agostino Gemelli University
}

Hospital, Rome, Italy. ${ }^{13}$ Department of Gastroenterology, Portuguese Oncology Institute of Porto, Porto, Portugal.

Received: 26 December 2020 Accepted: 23 March 2021

Published online: 01 April 2021

\section{References}

1. Jang S, Kim D, Cho J, et al. Primary needle-knife fistulotomy versus conventional cannulation method in a high-risk cohort of post-endoscopic retrograde cholangiopancreatography pancreatitis. Am J Gastroenterol. 2020;115:616-24.

2. Lopes L, Dinis-Ribeiro M, Rolanda C. Safety and efficacy of precut needleknife fistulotomy. Scand J Gastroenterol. 2014;49:759-65.

3. Lopes L, Dinis-Ribeiro M, Rolanda C. Early precut fistulotomy for biliary access: time to change the paradigm of "the later, the better"? Gastrointest Endosc. 2014;80:634-41.

4. Jin $\mathrm{YH}$, Jeong $\mathrm{S}$, Lee DH. Utility of needle-knife fistulotomy as an initial method of biliary cannulation to prevent post-ERCP pancreatitis in a highly selected at-risk group: a single-arm prospective feasibility study. Gastrointest Endosc. 2016;84:808-13.

5. Choudhary A, Winn J, Siddique S, et al. Effect of precut sphincterotomy on post-endoscopic retrograde cholangio-pancreatography pancreatitis: a systematic review and meta-analysis. World J Gastroenterol. 2014;20:4093-101.

6. Mavrogiannis C, Liatsos C, Romanos A, et al. Needle-knife fistulotomy versus needle-knife papillotomy for the treatment of common bile duct stones. Gastrointest Endosc. 1999:50:334-9.

7. Katsinelos P, Gkagkalis S, Chatzimavroudis G, et al. Comparison of three types of precut technique to achieve common bile duct cannulation: a retrospective analysis of 274 cases. Dig Dis Sci. 2012;57:3286-92.

8. Abu-Hamda EM, Baron TH, Simmons DT, et al. A retrospective comparison of outcomes using three different precut needle knife techniques for biliary cannulation. J Clin Gastroenterol. 2005;39:717-21.

9. Testoni P. Mariana A, Aabakken L et al. Papillary cannulation and sphincterotomy techniques at ERCP: European Society of Gastrointestinal Endoscopy (ESGE) Clinical Guideline. Endoscopy. 2016; 48:657-83.

10. Horiuchi A, Nakayama Y, Kajiyama M, Tanaka N. Effect of precut sphincterotomy on biliary cannulation based on the characteristics of the major duodenal papilla. Clin Gastroenterol Hepatol. 2007;5:1113-8.

11. Katsinelos P, Lazaraki G, Chatzimavroudis G, et al. The endoscopic morphology of major papillae influences the selected precut technique for biliary access. Gastrointest Endosc. 2015;81:1056

12. Kasmin FE, Cohen D, Batra S, et al JH. Needle-knife sphincterotomy in a tertiary referral center: efficacy and complications. Gastrointest Endosc. 1996; 44:48-53.

13. Saritas U, Ustundag $Y$, Harmandar F. Precut sphincterotomy: a reliable salvage for difficult biliary cannulation. World J Gastroenterol. 2013;19:1-7.

14. Lopes C, Canena J, Fernandes J, et al. Should we use papilla morphology to estimate the size of the terminal common bile duct during endoscopic retrograde cholangiopancreatography? Eur J Gastroenterol Hepatol. 2020;32:181-6.

15. Lerch M, Domschke W. Abraham Vater of the Ampulla (Papilla) of Vater. Gastrointest Endosc. 2000;118:379.

16. Vater A. Dissertatio anatomica quo novum bilis dicetilicum circa orifucum ductus choledochi ut et valvulosam colli vesicæ felleæ constructionem ad disceptandum proponit. Wittenberg 1720.

17. Lee TH, Bang BW, Park SH, Jeong S, Lee DH, Kim SJ. Precut fistulotomy for difficult biliary cannulation: Is it a risky preference in relation to the experience of an endoscopist? Dig Dis Sci. 2011:56:1896-903.

18. Haraldsson E, Lundell L, Swahn F, Enochsson L, Löhr J, Arnelo U. Endoscopic classification of the papilla of Vater. Results of an inter- and intraobserver agreement study. United Eur Gastroenterol J. 2017; 5: 504-10

19. Haraldsson E, Kylänpää L, Grönroos J, Saarela A, Toth E, Qvigstad G, et al. The macroscopic appearance of the major duodenal papilla influences bile duct cannulation: a prospective multicenter study by the Scandinavian Association for Digestive Endoscopy study group for ERCP. Gastrointest Endosc. 2019;90:957-63. 
20. Watanabe M, Okuwaki K, Kida M, Imaizuni H, Yamauchi H, Kaneko T, et al. Transpapillary biliary cannulation is difficult in cases with large oral protrusion of the duodenal papilla. Dig Dis Sci. 2019;64:2291-9.

21. Fink A, Kosecoff J, Chassin M, Brook RH. Consensus methods: characteristics and guidelines for use. Am J Public Health. 1984;74:979-83.

22. Cotton PB, Eisen GM, Aabakken L, et al. A lexicon for endoscopic adverse events: report of an ASGE workshop. Gastrointest Endosc 2010;71:446-54.

23. Cotton PB, Lehman G, Vennes J, et al. Endoscopic sphincterotomy complications and their management: an attempt at consensus. Gastrointest Endosc. 1991;37:383-93.

24. Harewood GC, Baron TH. As assessment of the learning curve for precut biliary sphincterotomy. Am J Gastroenterol. 2002;97:1708-12.

25. Donnellan F, Zeb F, Courtney G, et al. Suprapapillary needle-knife fistulotomy: a safe and effective method for accessing the biliary system. Surg Endosc. 2010;24:1937-80.

26. Dumonceau JM, Andriulli A, Elmunzer BJ, et al. Prophylaxis of post-ERCP pancreatitis: European Society of Gastrointestinal Endoscopy (ESGE) guideline-updated June 2014. Endoscopy. 2014;46:799-815.

27. Landis JR, Koch GG. The measurement of observer agreement for categorical data. Biometrics. 1977;33:159-74.

28. Inomata M, Terui T, Endo M. Anatomy of the papilla of Vater and strategies for cannulation of the desired ducts in ERCP (in Japanese with English abstract). Shokaki Naishikyo (Endoscopia Digestiva). 2008;20:1973-1803.

29. Matsushita M, Uchida K, Nishio A, Takakuwa H, Okazaki K. Small papilla: another risk factor for post-sphincterotomy perforation. Endoscopy. 2008;40:875-6.
30. Katsinelos P, Lazaraki G, Chatzimavroudis G, Zavos C, Kountouras J. The endoscopic morphology of major papillae influences the selected precut technique for biliary access. Gastrointest Endosc. 2015;81:1056.

31. Zhang QS, Han B, Xu JH, Gan P, Shen YC. Needle-knife papillotomy and fistulotomy improved the treatment outcome in patients with difficult biliary cannulation. Surg Endosc. 2016;30:5506-12.

32. Qian Y, Huang J, Zhang Y, Fan ZN. Cannulation of the intradiverticular papilla using a duodenoscope: Is it a safe method? World J Gastroenterol. 2014;20:10217-8.

33. Altonbary AY, Bahgat MH. Endoscopic retrograde cholangiopancreatography in periampullary diverticulum: The challenge of cannulation. World J Gastrointest Endosc. 2016;8:282-7.

34. Tyagi P, Sharma P, Sharma BC, Puri As. Periampullary diverticula and technical success of endoscopic retrograde cholangiopancreatography. Surg Endosc 2009; 23:1342-5

35. Adler DG. ERCP biliary cannulation difficulty as a function of papillary subtypes: a tale of shapes and Shar-Pei dogs. Gastrointest Endosc. 2019:90:964-5.

36. Viera A, Garrett J. Understanding interobserver agreement: the kappa statistic. Fam Med. 2005:37:360-3.

\section{Publisher's Note}

Springer Nature remains neutral with regard to jurisdictional claims in published maps and institutional affiliations.
Ready to submit your research? Choose BMC and benefit from:

- fast, convenient online submission

- thorough peer review by experienced researchers in your field

- rapid publication on acceptance

- support for research data, including large and complex data types

- gold Open Access which fosters wider collaboration and increased citations

- maximum visibility for your research: over $100 \mathrm{M}$ website views per year

At BMC, research is always in progress.

Learn more biomedcentral.com/submissions 